\title{
OFICINAS DE RECICLAGEM E REUTILIZAÇÃO DE RESÍDUOS SÓLIDOS NO CENTRO DE ESTUDOS SUPERIORES DE CAXIAS, MARANHÃO, BRASIL
}

\section{Elayne Irlene dos Santos Silva-Nunes ${ }^{1}$, Gonçalo Mendes da Conceição ${ }^{2}$, Luiz Alves de Souza Júnior ${ }^{3}$}

1 Graduada no Curso de Ciências Biológicas - Licenciatura da Universidade Estadual do Maranhão, Caxias-MA, Brasil, e-mail: enyalesilvanunescx@outlook.com

2 Professor Doutor da Universidade Estadual do Maranhão, Caxias-MA, Brasil

3 Professor pesquisador da Universidade Estadual do Maranhão, Caxias-MA, Brasil

Recebido em: 08/04/2016 - Aprovado em: 30/05/2016 - Publicado em: 20/06/2016 DOI: 10.18677/Enciclopedia_Biosfera_2016_137

Os problemas ambientais, decorrentes dos grandes acúmulos de lixo produzidos pelas ações antrópicas, são cenários de muitos debates, e para amenizar esses problemas buscam-se alternativas como a reciclagem e a reutilização de resíduos sólidos, que além de contribuir para limpeza do ambiente, gera renda para vários recicladores. Diante deste contexto, este trabalho teve o objetivo de implantar oficinas de reciclagem e reutilização de resíduos sólidos no Centro de Estudos Superiores de Caxias/Universidade Estadual do Maranhão (CESC/UEMA), visando sensibilizar os alunos e a comunidade sobre a importância de reciclar e reutilizar os resíduos sólidos, para contribuir com a limpeza e preservação do meio ambiente. Para realização deste trabalho foram selecionadas três turmas de alunos do Curso de Ciências Biológicas e uma do Curso de Ciências com Habilitação em Biologia perfazendo assim total de 75 alunos. Em cada turma foram aplicados questionários investigativos para avaliar o nível de conhecimento dos alunos. Foram ministradas palestras sobre conteúdos de educação ambiental para enriquecer o conhecimento dos alunos, e realizadas oficinas que resultaram na confecção de 200 objetos decorativos, utilizando materiais que foram coletados no CESC/UEMA. Portanto, este trabalho teve resultado muito significativo, pois além de aprenderem a confeccionar diversos objetos de decoração a partir da reciclagem de papel, e reutilização de garrafas PET, CDs, papelão e jornais, os alunos aprenderam a separar melhor os materiais, a por em prática os conhecimentos assimilados, e contribuir para a limpeza e preservação do meio ambiente.

PALAVRAS-CHAVE: Educação ambiental, lixo, meio ambiente 


\title{
RECYCLING AND REUSE WORKSHOPS OF SOLID WASTE IN THE CENTRO DE ESTUDOS SUPERIORES DE CAXIAS, MARANHÃO, BRAZIL
}

\begin{abstract}
Environmental problems arising from the large trash accumulations produced by human activities, are scenarios of much debate, and to alleviate these problems are sought alternatives such as recycling and reuse of solid waste, which also contribute to environmental cleanliness, generates income to various recyclers. Given this context, this study aimed implant of recycling and reuse workshops of solid waste in Centro de Estudos Superiores de Caxias/Universidade Estadual do Maranhão (CESC/UEMA) to sensitize students and the community about the importance of recycling and reusing solid waste, to contribute to the cleaning and preservation of the environment. For realization this work were selected three classes of students Biological Sciences Course and a group of Sciences course with Habilitation in Biology thus making total of 75 students. In each class were applied investigative questionnaires to assess the level of knowledge of students. Lectures were given on environmental education content to enrich the students' knowledge, and conducted workshops that resulted in the production of 200 decorative objects, using materials that were collected in the CESC / UEMA. So this study was very significant result, because in addition to learning to sew various decorative objects from paper recycling, and reuse of PET bottles, CDs, cardboard and newspapers, students also learned to better separate the materials, by in practice the assimilated knowledge, and also the contribute to the cleaning and preservation of the environment.
\end{abstract}

KEYWORDS: Environmental education, trash, environment

\section{INTRODUÇÃO}

Os problemas ambientais têm provocado muitos debates e discussões, tudo isso por consequência do acúmulo de lixo produzido pelas ações antrópicas. A cada dia milhares de toneladas de lixo são produzidas e descartadas em locais inadequados, contaminando o solo, a água, o ar atmosférico, e contribuindo para a proliferação de doenças, que conseqüentemente trás vários prejuízos à saúde dos seres humanos, do meio ambiente e das futuras gerações (RIBEIRO et al., 2010).

Porém, o que é o lixo? Em uma linguagem mais técnica, pode-se dizer que são resíduos sólidos, gerados pelas ações antrópicas, que geralmente são considerados inúteis e que, indiscriminadamente, são descartados no meio ambiente, ocasionando impactos no nível local, regional e global à saúde humana e planetária (ABNT, 2004). De acordo com RIBEIRO et al., (2010), o Brasil produz diariamente cerca de 250 mil toneladas de resíduos sólidos e cerca de $85 \%$ dessa produção é despejada a céu aberto, pois não há um destino correto para toda essa produção.

Diante dessa situação, uma proposta eficaz e que visa amenizar esses problemas e minimizar os acúmulos de lixo no meio ambiente é a reciclagem e a reutilização de resíduos sólidos. Estas, além de diminuírem a quantidade de resíduos, geram renda para várias famílias de catadores, ou seja, recicladores, e ainda reduz a extração de matérias-primas da natureza (RIBEIRO et al., 2010).

Inserida nesse contexto, a educação ambiental é muito importante, pois segundo SPIRONELLO et al., (2012) "esta pode ser compreendida como 
sinônimo de reflexão e ação, a qual se desenvolve a partir de um processo educativo, permanente e contínuo, superando a visão meramente ecológica, e incorporando no escopo das discussões, questões políticas, sociais, econômicas, culturais e ambientais". Em concordância SILVA et al., (2014) afirmam que a Educação Ambiental "vem exercer um papel fundamental de sensibilização e conscientização das pessoas, quanto às práticas atuais de consumo, utilização dos recursos naturais e descarte de resíduos", bastante presentes na sociedade atual.

Neste contexto, objetivou-se com o presente trabalho implantar oficinas de reciclagem e reutilização de resíduos sólidos no Centro de Estudos Superiores de Caxias/Universidade Estadual do Maranhão, visando sensibilizar os alunos e a comunidade sobre a importância de reciclar e reutilizar os resíduos sólidos, para contribuir com a limpeza e preservação do meio ambiente, e para incentivar a prática da educação ambiental.

\section{MATERIAL E MÉTODOS}

\section{Área de estudo}

O presente trabalho foi realizado no Centro de Estudos Superiores de Caxias/Universidade Estadual do Maranhão, localizado na zona urbana do Município de Caxias - Maranhão, na Praça Duque de Caxias, s/n, no Morro do Alecrim. O CESC conta com mais de 1.300 alunos, que frequentam os cursos de Biologia, Letras, Química, Física, Geografia, História, Matemática, Enfermagem, Medicina, e um programa de pós-graduação em Biodiversidade, Ambiente e Saúde.

\section{Seleção dos conteúdos e das turmas}

Inicialmente foi realizado levantamento bibliográfico por meio de pesquisas em artigos, livros e revistas científicas, para posterior seleção dos conteúdos e informações relevantes que foram abordados nas aulas teóricas e oficinas de reciclagem e reutilização de resíduos sólidos. Posteriormente foram selecionadas quatro disciplinas (turmas) de dois cursos de graduação do CESC/UEMA, as quais estão descritas abaixo na tabela 1, e respectivos turnos e quantidade de alunos.

TABELA 1. Relação dos cursos, disciplinas, turnos e respectivas quantidades de alunos das disciplinas que participaram das oficinas de reciclagem e reutilização de resíduos sólidos no CESC/UEMA.

\begin{tabular}{cccc}
\hline Curso de Graduação & Disciplina (Turma) & Turno & $\begin{array}{c}\text { Número } \\
\text { de alunos }\end{array}$ \\
\hline $\begin{array}{c}\text { Curso de Ciências } \\
\text { Biológicas - Licenciatura }\end{array}$ & $\begin{array}{c}\text { Educação e Legislação } \\
\text { Ambiental }\end{array}$ & Matutino & 30 \\
Curso de Ciências conômica & Matutino & 12 \\
Habilitação em Biologia & $\begin{array}{c}\text { Educação e Liogislogia } \\
\text { Ambiental }\end{array}$ & $\begin{array}{c}\text { Matutino } \\
\text { Noturno }\end{array}$ & 12 \\
\hline
\end{tabular}

\section{Seleção dos materiais}

Essa etapa se deu através da seleção dos materiais por meio de coletas semanais nos laboratórios, departamentos, biblioteca, lanchonetes, e xerox do 
CESC/UEMA. Foram selecionados vários materiais, que geralmente são descartados no lixo do CESC/UEMA, como papéis de xerox, CD's, garrafas PET's resultantes do uso em eventos que foram realizados na universidade, jornais, revistas, e caixas de papelão, caixas de leite, dentre outros resíduos sólidos.

\section{Elaboração de questionário investigativo}

Com base nos conteúdos de Educação Ambiental que foram selecionados a partir do levantamento bibliográfico, foram elaboradas sete questões objetivas para o questionário investigativo, que foi utilizado para avaliar o nível de conhecimento dos alunos, antes da realização das aulas e das oficinas de reciclagem e reutilização de resíduos sólidos.

\section{Aulas teóricas e oficinas}

As aulas teóricas e as oficinas foram ministradas nos horários de aula normal de cada turma selecionada. Foram ministradas aulas com slides (Microsoft PowerPoint), abordando os principais conceitos e diversas outras informações sobre temas como: o que é o meio ambiente; educação e preservação ambiental; o lixo; o princípio dos R's (Reciclar, Reduzir, Reutilizar, Repensar, Recusar, Reeducar, Reintegrar, Replanejar) da educação ambiental; coleta e separação de materiais; reciclagem e reutilização de resíduos sólidos e sustentabilidade.

Posteriormente foram aplicadas as oficinas. Nestas foram confeccionados diversos objetos decorativos como: vários porta-lápis de garrafa PET decorados com paetês, com TNT e retalhos de tecidos; jarros e cestas, ambos feitos de papéis, jornais e revistas; e jarros de garrafa PET que foram decorados com E.V.A. e com cola glitter; caixas de jóias feitas com CD's, papel cartão, E.V.A. e retalhos de tecidos; e porta lápis de caixas de leite decorados com papéis de xerox, E.V.A. e retalhos de tecidos.

\section{Exposição dos objetos confeccionados nas oficinas}

Para finalizar as atividades, foram realizadas no CESC/UEMA e em outras IES exposições dos materiais confeccionados nas oficinas, para que toda a comunidade apreciasse os resultados do projeto e se sensibilizasse sobre a importância de reciclar e reutilizar os materiais para preservar o meio ambiente.

\section{Análise de dados}

A análise de dados foi por meio da comparação entre os resultados obtidos nos questionários investigativos aplicados nas turmas selecionadas, para aplicação das atividades do projeto. Os resultados foram analisados quantitativamente, realizando o somatório e a porcentagem dos resultados obtidos. Cada uma das questões foi analisada quanto ao conteúdo, e as alternativas mais assinaladas. Fez-se a comparação das respostas das turmas que já tiveram aulas de educação ambiental, com as respostas das turmas que ainda não tiveram essas aulas em uma disciplina específica.

\section{RESULTADOS E DISCUSSÃO}

\section{Conceito de meio ambiente}

Analisando as respostas dos alunos das diferentes disciplinas, observouse que ao serem questionados sobre o conceito de meio ambiente (Figura 1), a maioria dos alunos, $73,3 \%, 47,7 \%$ e $83,3 \%$ respectivamente, optaram pela 
alternativa $\mathrm{B}$, e relacionaram o meio ambiente a relação ecológica entre os seres vivos e não-vivos. Enquanto que outra porcentagem dos alunos, $38,1 \%$, e $41,7 \%$ optaram pela alternativa $\mathrm{D}$, e relacionaram 0 meio ambiente, ao ambiente ocupado pelo ser humano.

Percebe-se então que os alunos entendem que existe uma relação entre os seres vivos e o ambiente e que de certa forma essas relações ecológicas são importantes, pois contribuem para o equilíbrio ecológico do planeta, e segundo GUIMARÃES (1995) todos esses elementos relacionam-se influenciando e sofrendo influencias entre si, pois não existe a separação entre o meio ambiente e os seres vivos.

Analisando ainda, as respostas dos alunos, observou-se que um menor percentual optou pela alternativa $\mathrm{C}$, respondendo que o meio ambiente são as relações dos homens com a natureza para preservação dos recursos naturais, sendo que apenas a turma de Botânica Econômica não optou pela mesma alternativa das demais turmas.

Como pode-se observar, quando se trata do conceito de meio ambiente, tanto os alunos da disciplina de Educação Ambiental, quanto os alunos das disciplinas Botânica Econômica e História da Biologia (que não possuem uma disciplina específica sobre Educação Ambiental), possuem um conhecimento amplo de que o meio ambiente é a relação ecológica entre os seres vivos e nãovivos, e que além disso, sabem que os seres humanos, fazem parte do meio ambiente, onde vivem, e que é importante preservá-lo. Sobre isso, OLIVEIRA \& MEDEIROS (2010), afirmam que o conhecimento acerca do meio ambiente vai muito além do conceito ecológico abrangendo a existência do homem em sociedade e as relações constituídas por este.

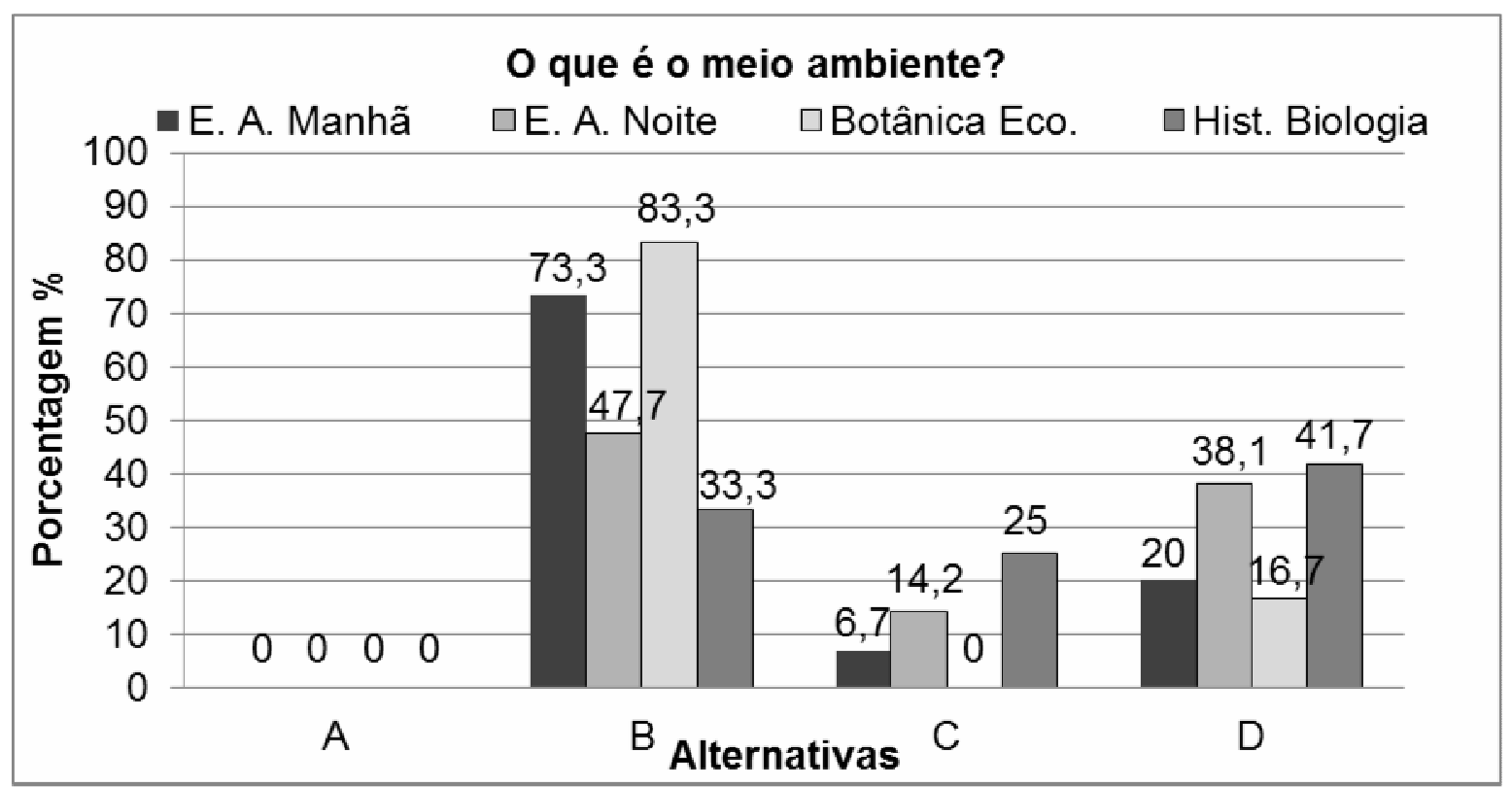

FIGURA 1. Percentual das respostas dos alunos quanto ao conceito de meio ambiente. Legenda: E. A. Manhã: Educação e Legislação Ambiental/Manhã (Curso: Ciências BiológicasLicenciatura); E. A. Noite: Educação e Legislação Ambiental/Noite (Curso: Ciências com Habilitação em Biologia); Botânica Eco.: Botânica Econômica (Curso: Ciências BiológicasLicenciatura); Hist. Biologia: História da Biologia (Curso: Ciências Biológicas-Licenciatura).

Alternativas - A: Todos os seres vivos. B: A relação ecológica entre os seres vivos e não-vivos; C: Relações dos homens com a natureza para preservação dos recursos naturais; $D$ : O ambiente em que vivemos. 


\section{A importância da coleta seletiva do lixo}

Ao analisar as respostas dos alunos com relação à importância da coleta seletiva do lixo (Figura 2), observou-se que a maior parte dos alunos, 47,7\%,75\% e $66,7 \%$ respectivamente, optaram pela alternativa B, respondendo que a importância da coleta seletiva é a limpeza do meio ambiente e redução da poluição. Além disso, observou-se que um número menor de alunos optou pelas alternativas $C$ e $D$, ressaltando que a importância da coleta seletiva seria a diminuição da quantidade de lixo e a preservação dos recursos naturais. Entretanto alguns alunos (56,7\%) optaram pela alternativa A, que seria no caso a resposta mais correta para a questão em análise, que ressalta que a importância seria a "separação correta de plástico, vidro, papel e metal".

De acordo com MARTINS et al., (2011), além de se tratar de um sistema de recolhimento de materiais recicláveis, a coleta seletiva é um processo de gestão e educação ambiental, que visa sensibilizar a sociedade acerca dos desperdícios de materiais vindos da natureza e alertar para a questão do consumismo acentuado. Além disso, pode-se dizer que a coleta seletiva tem papel importante na recuperação de materiais que foram retirados da natureza.

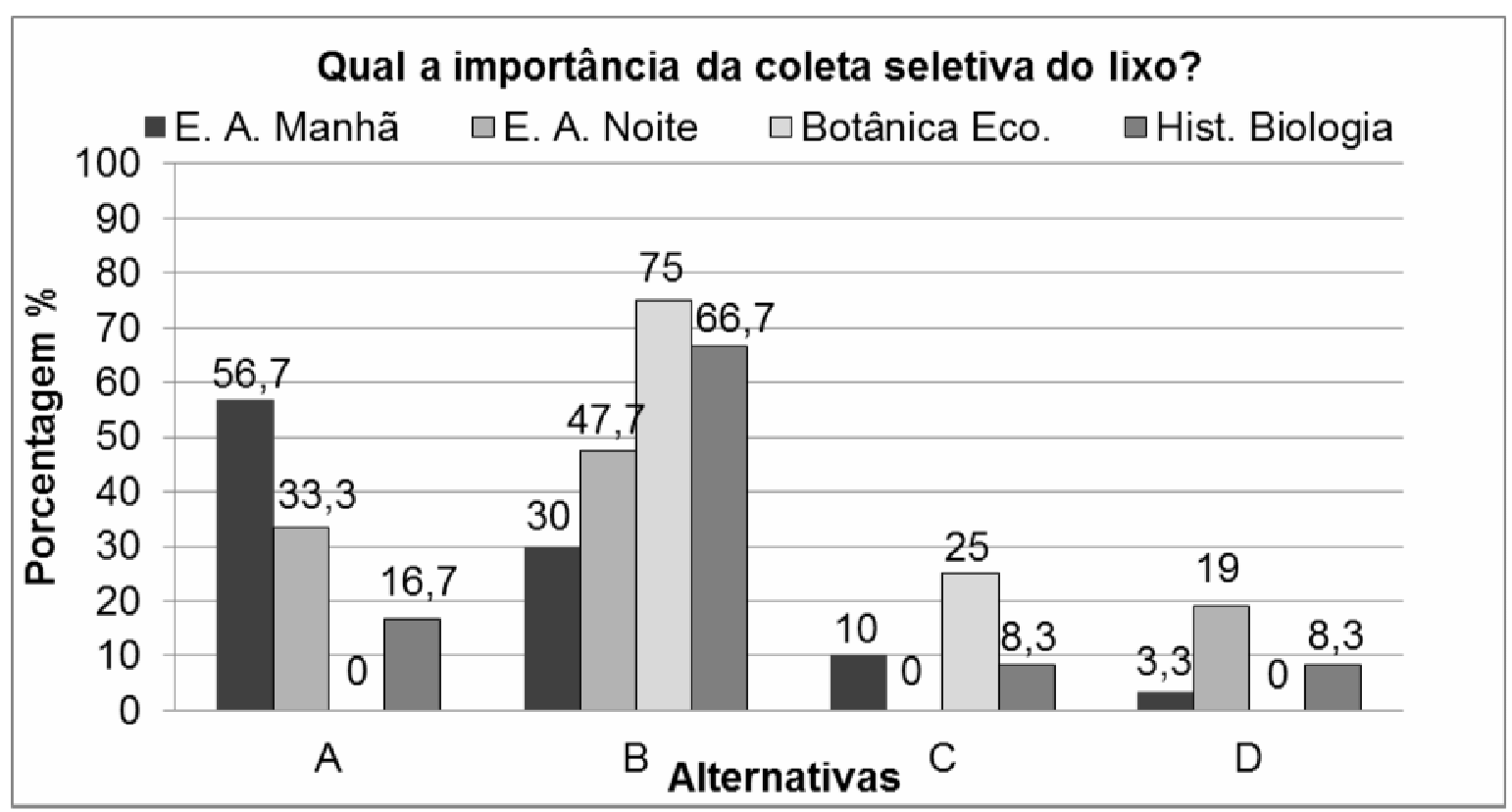

FIGURA 2. Percentual das respostas dos alunos quanto à importância da coleta seletiva do lixo.

Legenda: E. A. Manhã: Educação e Legislação Ambiental/Manhã (Curso: Ciências BiológicasLicenciatura); E. A. Noite: Educação e Legislação Ambiental/Noite (Curso: Ciências com Habilitação em Biologia); Botânica Eco.: Botânica Econômica (Curso: Ciências BiológicasLicenciatura); Hist. Biologia: História da Biologia (Curso: Ciências Biológicas-Licenciatura).

Alternativas - A: Separação correta de plástico, vidro, papel e metal; B: Limpeza do meio ambiente e redução da poluição; C: Diminuição da quantidade de lixo; D: Preservação dos recursos naturais.

\section{Conceito de poluição}

Em relação ao conceito de poluição (Figura 3), observou-se que $100 \%$ dos alunos das disciplinas Educação e Legislação Ambiental (Manhã), Botânica Econômica e História da Biologia, e 85,7\% dos alunos da turma de Educação e Legislação Ambiental (Noite) optaram pela alternativa B, que afirmava que 
poluição é a "Contaminação do meio ambiente resultante das ações dos homens". Ações estas como o consumismo exagerado de produtos industrializados e o descarte de resíduos sólidos em lugares inadequados que acabam contribuindo para proliferação de insetos e doenças, e para degradação ambiental (RIBEIRO et al., 2010). Em concordância GALLO \& GUENTHER (2015) afirmam que a "geração e acúmulo de resíduos sólidos nos centros urbanos são um dos maiores problemas ambientais da atualidade".

Ainda analisando as respostas dos alunos é notável que uma menor porcentagem dos alunos da disciplina de Educação e Legislação Ambiental (Noite) optaram pelas alternativas A e C, que conceituam poluição como sendo o "ambiente sujo" e "jogar lixo nas ruas e nos rios". Atitudes estas que sem dúvida, contaminam o ambiente e interferem na qualidade ambiental.

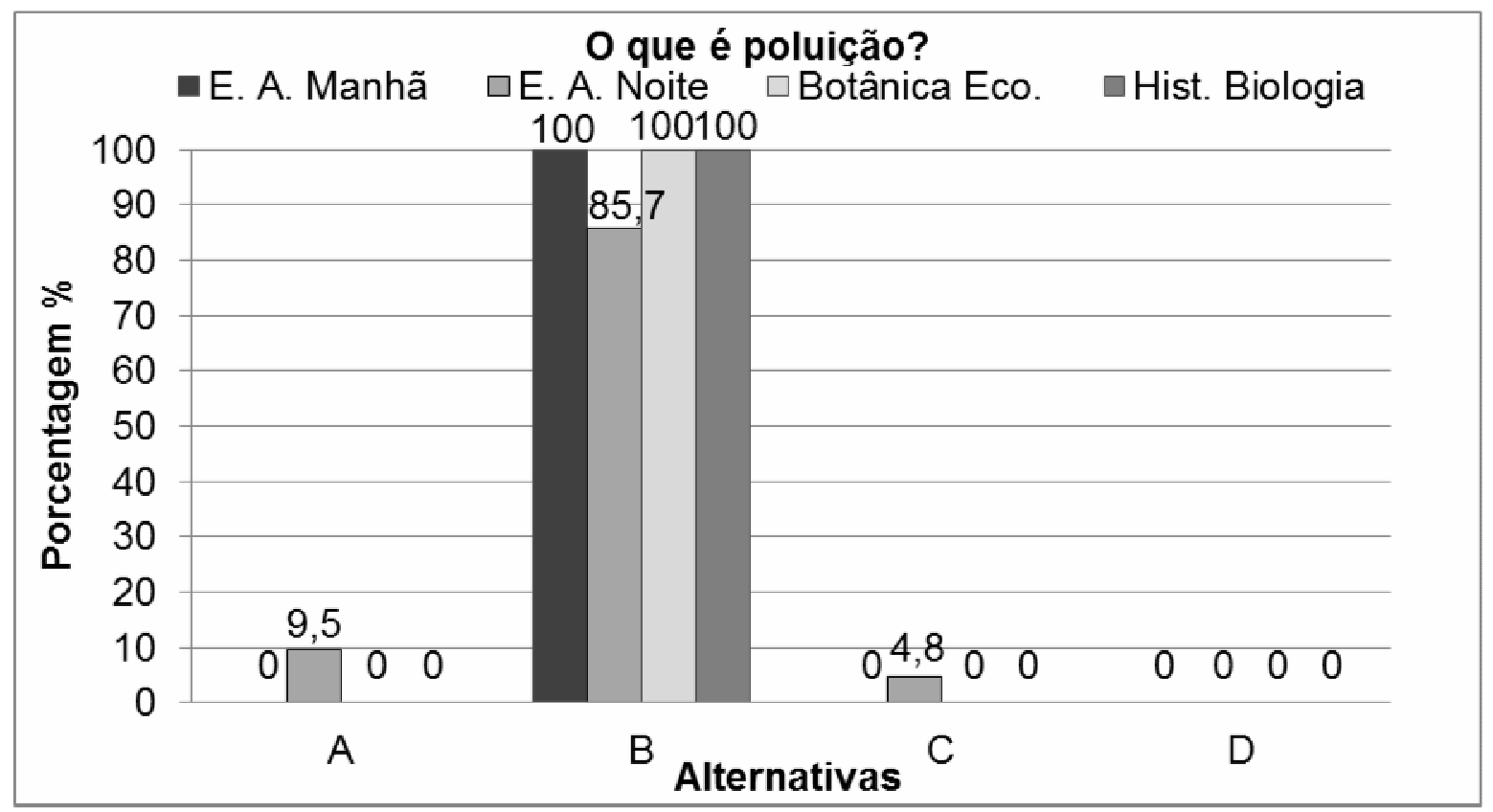

FIGURA 3. Percentual das respostas dos alunos quanto ao conceito de poluição. Legenda: E. A. Manhã: Educação e Legislação Ambiental/Manhã (Curso: Ciências BiológicasLicenciatura); E. A. Noite: Educação e Legislação Ambiental/Noite (Curso: Ciências com Habilitação em Biologia); Botânica Eco.: Botânica Econômica (Curso: Ciências BiológicasLicenciatura); Hist. Biologia: História da Biologia (Curso: Ciências Biológicas-Licenciatura).

Alternativas - A: Ambiente sujo; B: Contaminação do meio ambiente resultante das ações dos homens; C: Jogar lixo nas ruas, nos rios; D: Sujar ambientes públicos.

\section{Ações para diminuir a quantidade de lixo no ambiente}

Ao analisar as respostas dos alunos com relação a "ações que podem ser feitas para diminuir a quantidade de lixo no ambiente" (Figura 4), observou-se que a maior parte dos alunos, a exceção os alunos da disciplina Educação e Legislação Ambiental (Noite) que representaram apenas 9,5\%, optaram pela alternativa B, respondendo então que as ações seriam a "coleta seletiva do lixo", que é uma das medidas mais viáveis, que contribui para a reciclagem desses resíduos, e colabora para boa qualidade dos resíduos sólidos selecionados para reciclagem, reduz os gastos públicos de tratamento e acomodação final do lixo, reduz o consumo de energia e a extração de matérias primas da natureza, assim como a degradação ambiental e a proliferação de vetores de doenças. 
A maioria dos alunos $(76,2 \%)$ da disciplina de Educação e Legislação Ambiental (Noite) optaram pela alternativa A respondendo que as ações seriam a "construção de aterros sanitários", enquanto outros $14,3 \%, 8,3 \%$ e $6,7 \%$ dos alunos das demais disciplinas optaram pela alternativa $D$, respondendo que seria "manter o ambiente sempre limpo", porém, sabe-se que os aterros sanitários, apesar de serem técnicas de disposição de resíduos sólidos urbanos no solo, podem trazer riscos ao ambiente e a saúde pública, pois quando mal planejados e implantados em lugares inadequados, podem comprometer as águas subterrâneas e superficiais.

Como salienta OLIVEIRA et al. (2015) "os impactos causados pela destinação inadequada dos resíduos sólidos vão desde impactos ambientais (água, solo, ar, fauna, flora) até impactos socioeconômicos e de saúde pública.

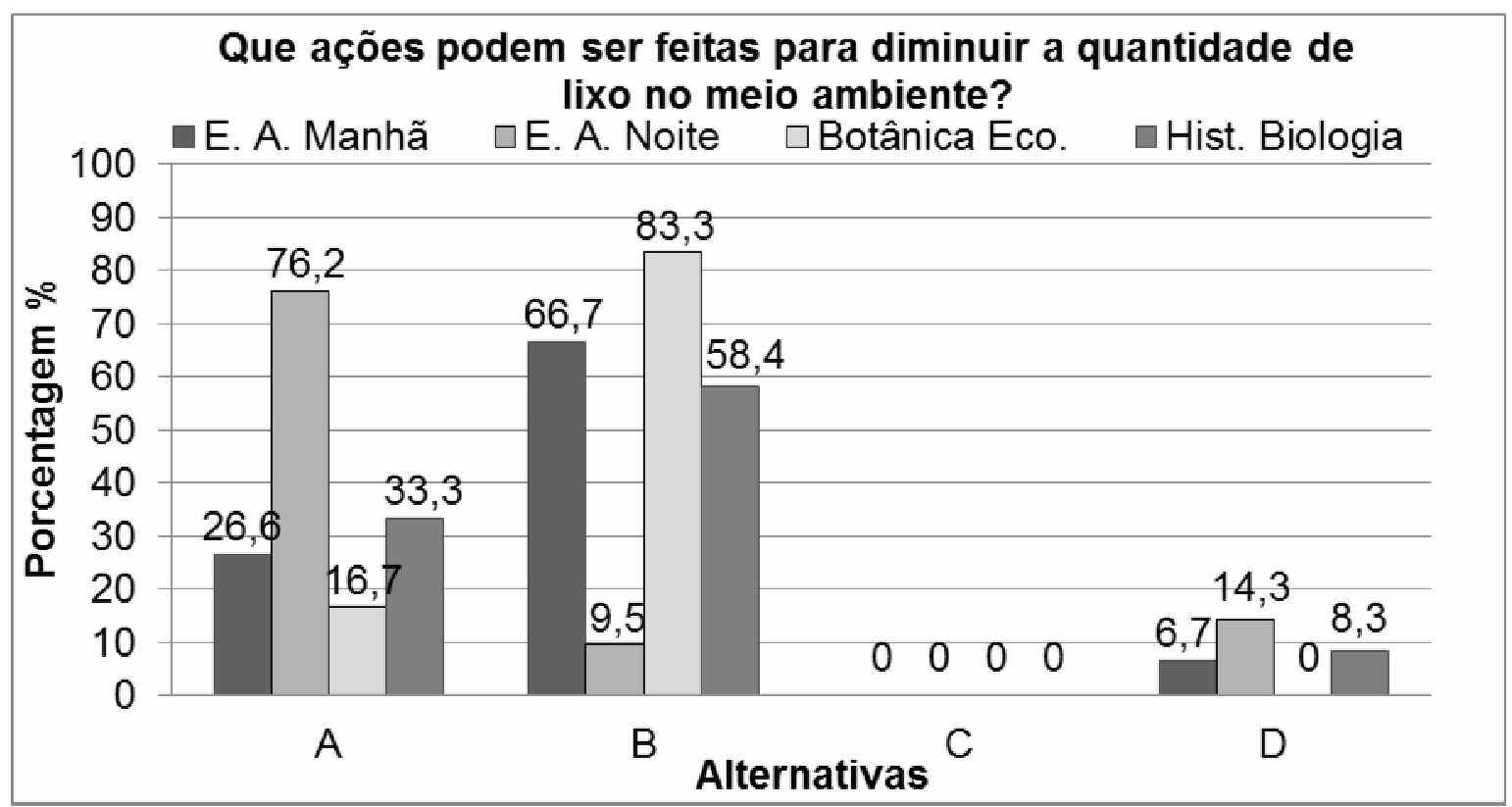

FIGURA 4. Percentual das respostas dos alunos quanto a ações que podem ser tomadas para diminuir a quantidade de lixo no ambiente.

Legenda: E. A. Manhã: Educação e Legislação Ambiental/Manhã (Curso: Ciências BiológicasLicenciatura); E. A. Noite: Educação e Legislação Ambiental/Noite (Curso: Ciências com Habilitação em Biologia); Botânica Eco.: Botânica Econômica (Curso: Ciências BiológicasLicenciatura); Hist. Biologia: História da Biologia (Curso: Ciências Biológicas-Licenciatura).

Alternativas - A: A construção de aterros sanitários; B: Coleta seletiva do lixo; C: A queima do lixo; D: Manter o ambiente sempre limpo.

\section{Conceito da palavra reciclar}

Em relação ao conceito da palavra reciclar, observou-se ao analisar as respostas dos alunos (Figura 5), que mais de $50 \%$ optaram pela alternativa $\mathrm{A}$, e responderam que reciclar é "transformar objetos materiais usados em novos produtos para o consumo".

Observou-se que uma parte significativa dos alunos (20\%) da disciplina de Educação e Legislação Ambiental (Manhã), 14,3\% da disciplina de Educação e Legislação Ambiental (Noite), $50 \%$ dos alunos da disciplina de Botânica Econômica e 8,3\% optaram pela alternativa $\mathrm{D}$, respondendo que reciclar é "trazer de volta ao ciclo produtivo o que poderia ser jogado no lixo". 
Ainda analisando os resultados obtidos observou-se que um menor percentual dos alunos das disciplinas, optaram pelas alternativas $\mathrm{B}$ e $\mathrm{C}$, que respondem respectivamente que reciclar é o "processamento de materiais e resíduos sólidos", "utilizar garrafas e papéis em casa em vez de jogar no lixo".

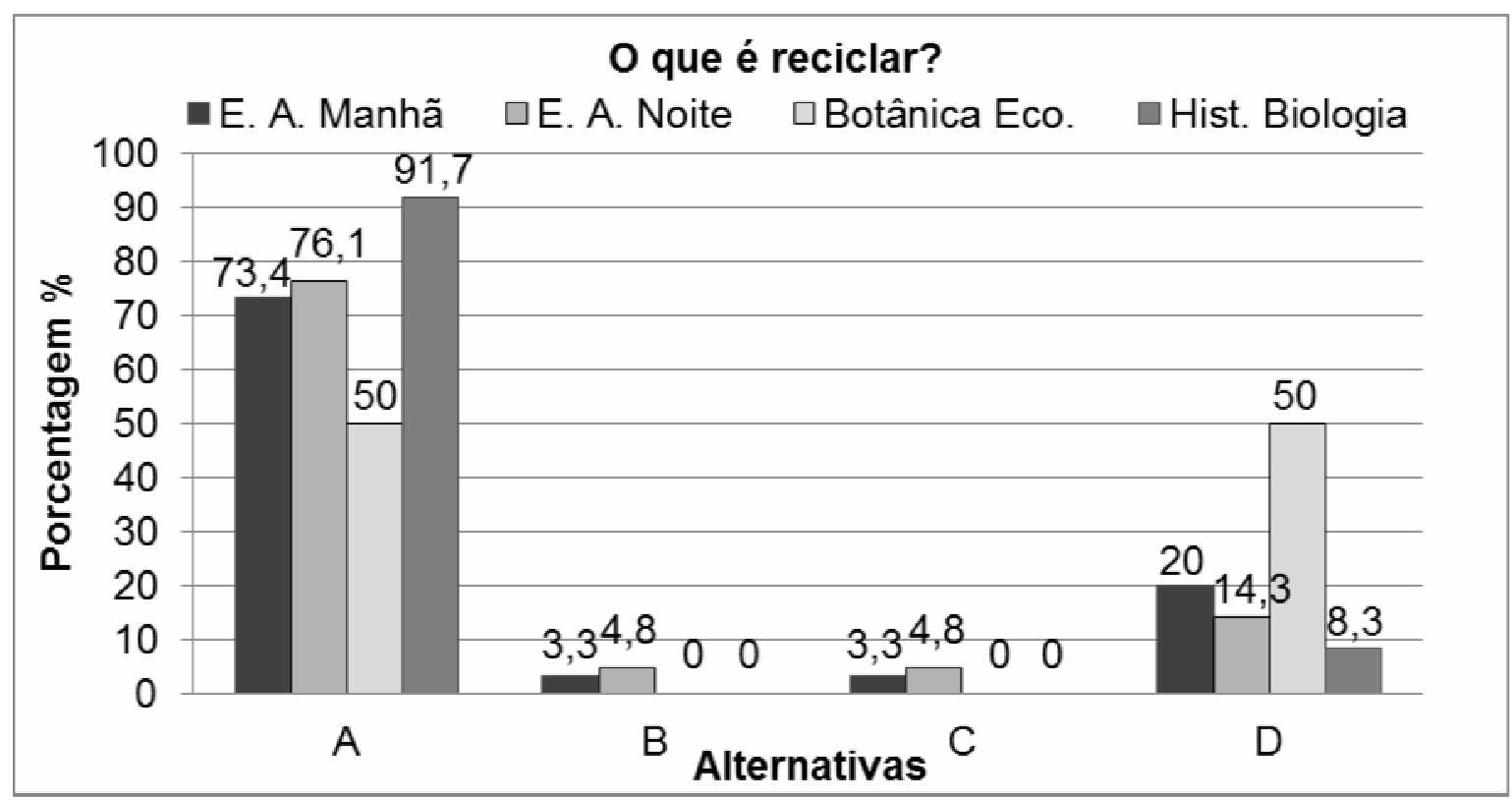

FIGURA 5. Percentual das respostas dos alunos quanto ao conceito da palavra reciclar.

Legenda: E. A. Manhã: Educação e Legislação Ambiental/Manhã (Curso: Ciências BiológicasLicenciatura); E. A. Noite: Educação e Legislação Ambiental/Noite (Curso: Ciências com Habilitação em Biologia); Botânica Eco.: Botânica Econômica (Curso: Ciências BiológicasLicenciatura); Hist. Biologia: História da Biologia (Curso: Ciências Biológicas-Licenciatura).

Alternativas - A: Transformar objetos materiais usados em novos produtos para o consumo; B: Processamento de materiais e resíduos sólidos; C: Utilizar garrafas e papéis em casa em vez de jogar no lixo; D: Trazer de volta ao ciclo produtivo o que poderia ser jogado no lixo.

\section{Conceito da palavra reutilizar}

Sobre o conceito da palavra reutilizar (Figura 6), observou-se que os maiores percentuais, das respostas obtidas com relação a questão em análise, foram dos alunos das disciplinas Educação e Legislação Ambiental (Manhã e Noite), que optaram pela alternativa $A$, respondendo que reutilizar é "reaproveitar materiais como papel, plástico, vidro e metal", e $50 \%$ são alunos da disciplina de Botânica Econômica, e outros 33,3\% da disciplina de História da Biologia que optaram pela mesma alternativa.

Observou-se que outras percentagens $(9,5 \%, 50 \%, 25 \%$ e $41,7 \%)$ dos alunos optaram pelas alternativas B, C e D, respondendo que reutilizar é respectivamente "decorar garrafas e papéis para fazer objetos de decoração", "ampliar a vida útil de um produto e economizar na extração de matérias-primas vindas da natureza", e "não jogar fora materiais que ainda podem ser usados". Essas atitudes são essenciais, e são conceitos corretos sobre reutilizar, que na verdade se complementam, e que segundo RIBEIRO et al., (2010), são soluções indispensáveis. 


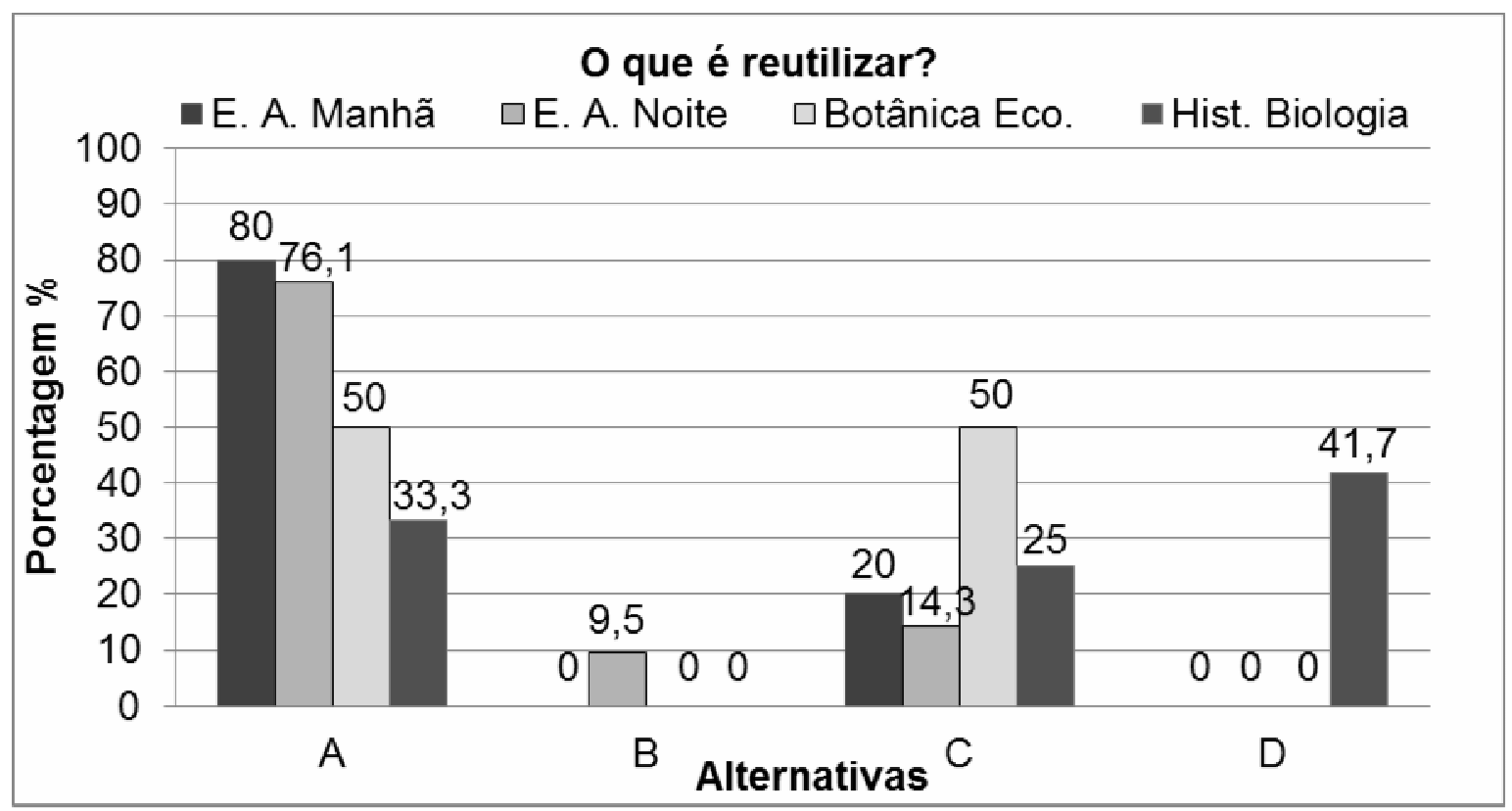

FIGURA 6. Percentual das respostas dos alunos quanto ao conceito da palavra reutilizar.

Legenda: E. A. Manhã: Educação e Legislação Ambiental / Manhã (Curso: Ciências BiológicasLicenciatura); E. A. Noite: Educação e Legislação Ambiental / Noite (Curso: Ciências com Habilitação em Biologia); Botânica Eco.: Botânica Econômica (Curso: Ciências BiológicasLicenciatura); Hist. Biologia: História da Biologia (Curso: Ciências Biológicas-Licenciatura).

Alternativas - A: Reaproveitar materiais como papel, plástico, vidro e metal; B: Decorar garrafas e papéis para fazer objetos de decoração; C: Ampliar a vida útil de um produto e economizar na extração de matérias-primas vindas da natureza; D: Não jogar fora materiais que ainda podem ser usados.

\section{Conceito da palavra lixo}

Analisando as respostas obtidas com relação ao conceito de lixo (Figura 7), observou-se que $100 \%$ dos alunos das disciplinas Educação e Legislação Ambiental (Manhã), Botânica Econômica e Historia da Biologia optaram pela alternativa $B$, respondendo que lixo são "resíduos sólidos resultantes das atividades humanas, que se acumulam no meio ambiente". Neste aspecto percebe-se que os alunos sabem que a origem do lixo esta relacionada às ações antrópicas, e que o acúmulo de lixo gerado pelos humanos contribuem para a degradação ambiental. De acordo com ALONSO (2001) o lixo é gerado todos os dias pelas diversas atividades econômicas da sociedade, trazendo consequências sérias a qualidade do ambiente, o que é hoje considerado um dos grandes problemas para a vida no planeta.

Já analisando as respostas dos alunos da disciplina Educação e Legislação Ambiental (Noite), observou-se que 90,4\% dos alunos optaram pela alternativa $B$, porém uma pequena parte da turma, que ao somar resultou em 9,6\% optaram pelas alternativas A e C, conceituam o lixo como restos de alimentos e materiais descartáveis. Estes por sua vez podem ser considerados lixo, uma vez que além de poluírem o ambiente contribuem para proliferação de doenças afetando a qualidade de saúde dos seres vivos e do próprio ambiente (OLIVEIRA et al., 2015). Segundo RIBEIRO et al., (2010), os restos de alimentos são considerados lixo de origem domiciliar, e geralmente são descartados junto com outros resíduos. Porém, se forem reaproveitados no processo de 
compostagem, em vez de poluírem irão contribuir para a ciclagem de nutrientes no meio ambiente.

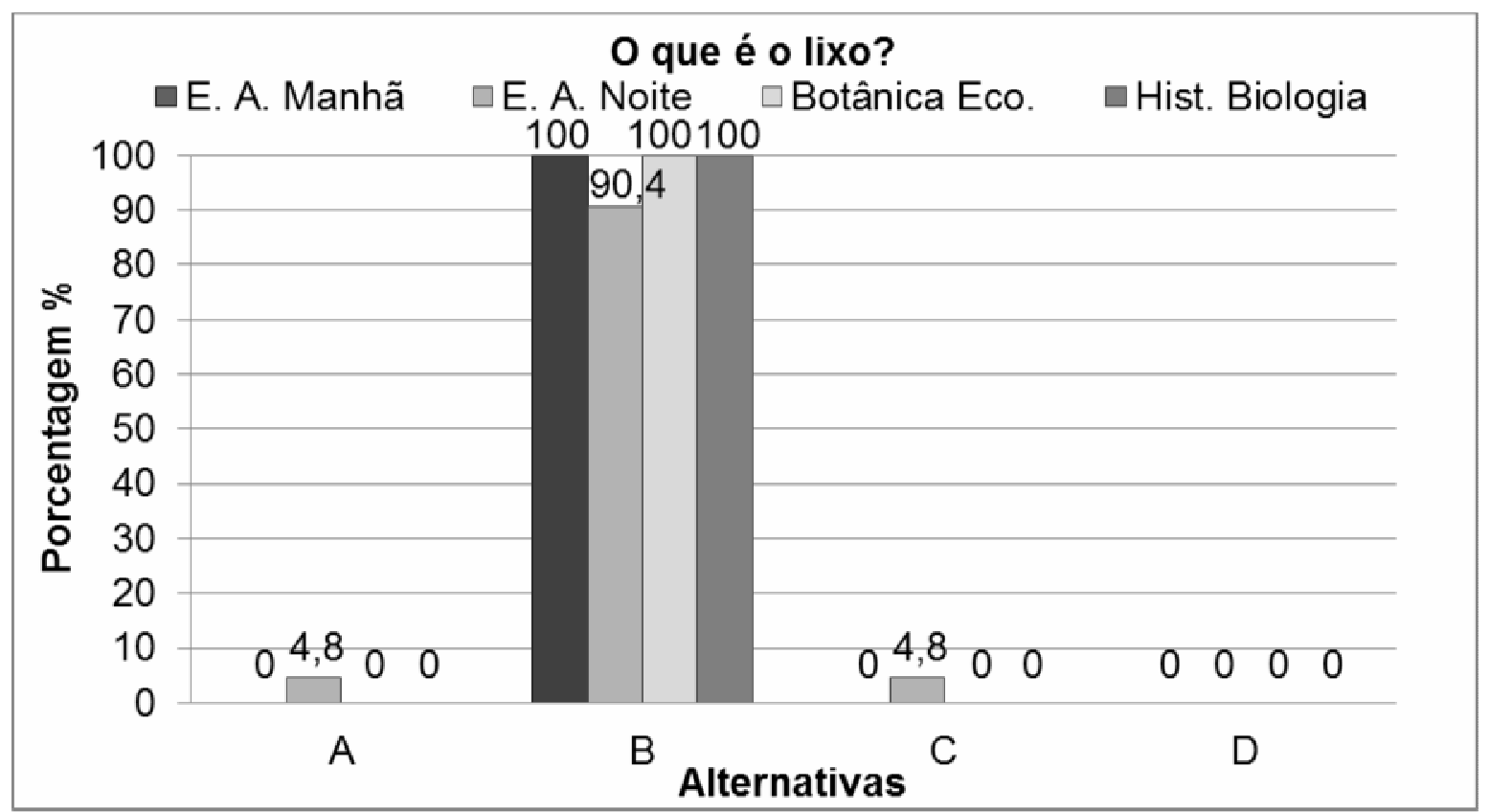

FIGURA 7. Percentual das respostas dos alunos quanto ao conceito de "lixo".

Legenda: E. A. Manhã: Educação e Legislação Ambiental/Manhã (Curso: Ciências BiológicasLicenciatura); E. A. Noite: Educação e Legislação Ambiental/Noite (Curso: Ciências com Habilitação em Biologia); Botânica Eco.: Botânica Econômica (Curso: Ciências BiológicasLicenciatura); Hist. Biologia: História da Biologia (Curso: Ciências Biológicas-Licenciatura).

Alternativas - A: Restos de alimentos; B: Resíduos sólidos resultantes das atividades humanas, que se acumulam no meio ambiente; C: Materiais descartáveis; D: Materiais contaminantes.

\section{Aulas teóricas e oficinas}

Durante as aulas teóricas, que foram ministradas após a aplicação do questionário investigativo, foram abordados diferentes conteúdos sobre educação ambiental, como: o que é o meio ambiente; educação e preservação ambiental; o lixo; o princípio dos R's da educação ambiental; coleta e separação de materiais; reciclagem e reutilização de resíduos sólidos e sustentabilidade.

Em todas as quatro disciplinas, observou-se que os alunos mantiveramse bastante atentos aos conteúdos, fizeram várias perguntas, demonstraram ter curiosidades sobre o tema, esclareceram dúvidas, relataram situações vivenciadas por eles. Sem dúvida foram momentos de grandes aprendizagens, tanto para os alunos quanto para a ministrante.

Já com relação às oficinas de reciclagem e reutilização de resíduos sólidos, foram momentos ainda melhores, pois os alunos puderam aprender novas formas de reciclar e reutilizar os resíduos sólidos (como as garrafas PET's, papéis, CD’s, entre outros materiais) que geralmente são encontrados em casa, na universidade e em vários lugares.

Nas oficinas os alunos organizaram-se em grupos e colocaram em prática a criatividade. Fizeram vários objetos decorativos como jarros, porta joias, porta lápis, cofres, dentre outros (Figura 8). Essas atividades foram importantes, pois além de contribuírem para uma melhor aprendizagem dos conteúdos de educação ambiental, contribuíram para reforçar valores como o trabalho em 
grupo, a solidariedade, o compartilhamento, o respeito, a união, sem deixar de lado a preocupação com a preservação ambiental.

Segundo LOPES (2011) o desenvolvimento destes valores sociais são determinantes, sob o aspecto ambiental, pois promovem um comportamento norteado para a transformação da realidade em que estes se inserem. Além disso, foi por meio das oficinas que os alunos aprenderam a separar melhor os materiais, e dar uma nova finalidade aos resíduos sólidos, contribuindo assim para a limpeza do CESC/UEMA e do meio ambiente.

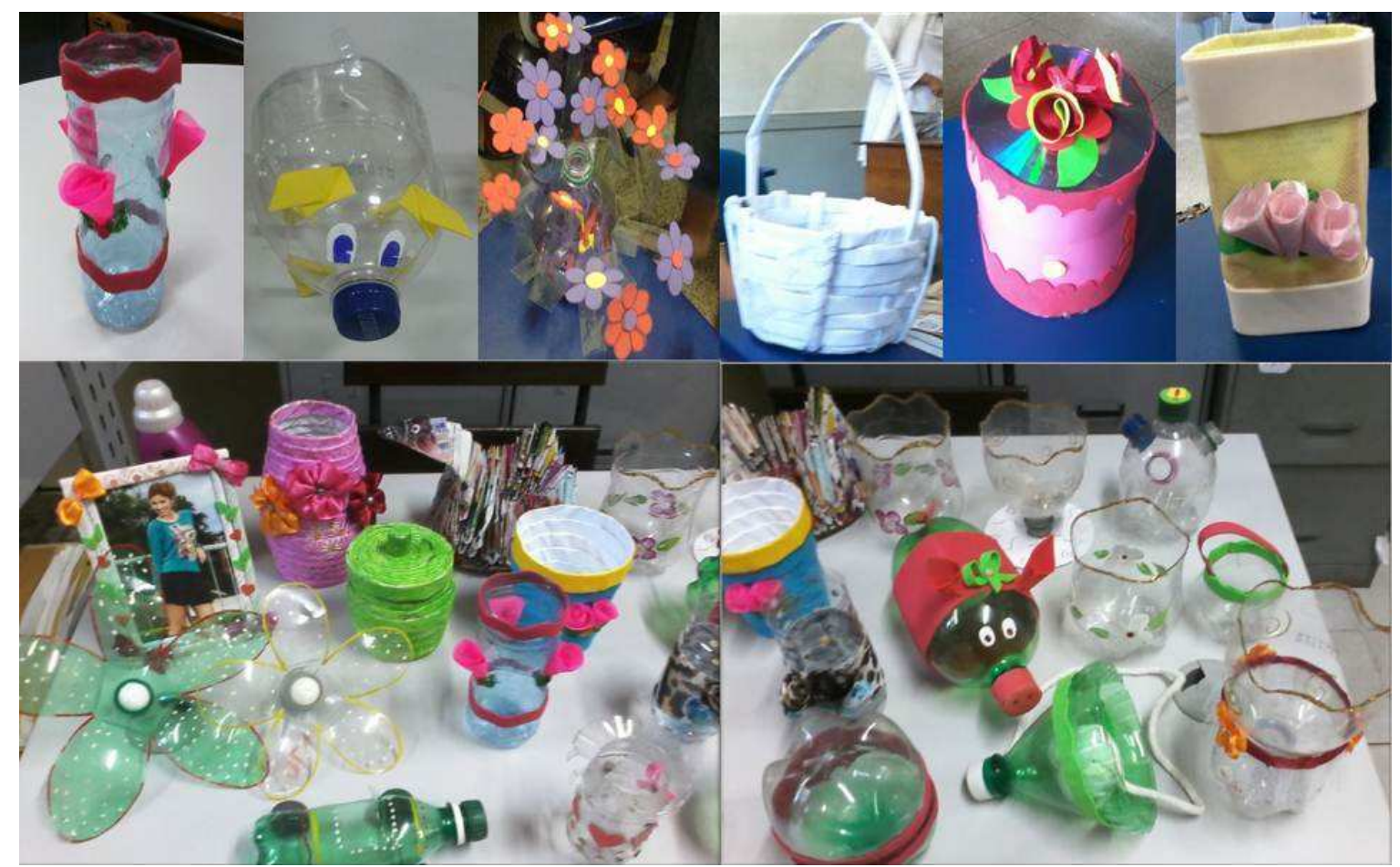

FIGURA 8. Objetos decorativos que foram confeccionados nas oficinas de reciclagem e reutilização de materiais nas duas turmas de Educação e Legislação Ambiental, Botânica Econômica e História da Biologia.

\section{A exposição dos materiais}

A exposição dos materiais confeccionados nas oficinas de reciclagem e reutilização de materiais foi realizada no CESC/UEMA, no dia 5 de junho de 2015 (Dia Mundial do Meio Ambiente), mesmo dia em que aconteceu a exposição e apresentação de trabalhos acadêmicos do JORBIOS - Jornada Acadêmica de Biologia e Saúde (Figura 9). Foram expostos em mesas diversos objetos de decoração e utensílios do lar que foram confeccionados a partir de materiais como papéis de xerox, jornais, revistas, papelão, CD's, garrafas PET's, isopor, caixas de leite, retalhos de tecidos, entre outros materiais. Além disso, foi exposto banner sobre o projeto.

$\mathrm{Na}$ ocasião, estavam presentes estudantes e professores do CESC/UEMA, estudantes e professores de outras instituições de ensino como UFPA, UFMA, IFPI, e IFMA. As pessoas que prestigiaram o evento conheceram os resultados do projeto e obtiveram um pouco mais de conhecimento com relação à Educação Ambiental, compreendendo, assim, a importância de reciclar e reutilizar os resíduos sólidos para preservar o meio ambiente. 
Foi realizada uma exposição dos materiais confeccionados nas oficinas de reciclagem e reutilização de resíduos sólidos, na Universidade Federal do Piauí (Evento: Escolas Sustentáveis), neste evento estavam presentes alunos, universitários, professores e pesquisadores de várias regiões próximas, e que de certa forma, puderam obter mais conhecimentos, entender a importância da educação ambiental para a preservação ambiental e puderam colaborar com novas ideias para o projeto, gerando um momento muito enriquecedor (Figura 9).

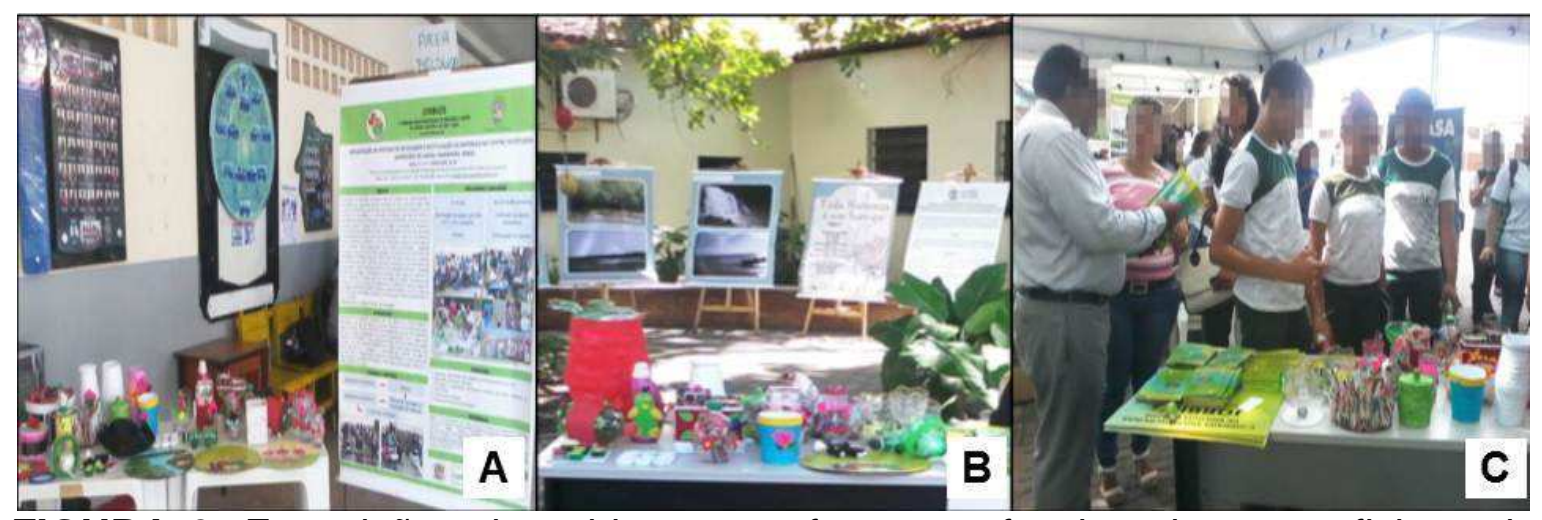

FIGURA 9. Exposições dos objetos que foram confeccionados nas oficinas de reciclagem e reutilização de resíduos sólidos no CESC/UEMA. Em A exposição de banner e dos objetos decorativos, no JORBIOS 2015. Em B e C exposição dos objetos decorativos na UFPI (Evento: Escolas Sustentáveis).

\section{CONCLUSÕES}

Os resultados da implantação das oficinas de reciclagem e reutilização de resíduos sólidos no Centro de Estudos Superiores de Caxias foram muito significativos, pois em cada encontro notava-se o envolvimento dos alunos nas atividades desenvolvidas, a curiosidade deles diante dos temas estudados nas aulas teóricas, o interesse em aprender mais e enriquecer o conhecimento sobre a temática ambiental e a criatividade nas oficinas aliada à vontade de aprender inúmeras formas de reutilizar e de dar novas finalidades aos resíduos sólidos, o que resultou em motivação para a elaboração de outros projetos na mesma linha de pesquisa e que ultrapassaram os limites da universidade, expandindo-se para escolas, comunidades, e para a participação em eventos locais e regionais.

Assim ao analisar todas as etapas durante o desenvolvimento deste trabalho, notou-se que é necessário a Educação Ambiental no contexto escolar, e em todas as áreas do conhecimento, uma vez que além de reforçar valores sociais e elevar o nível de conhecimentos das pessoas, a temática ambiental contribui para a qualidade de vida do planeta e para a formação de uma sociedade mais consciente. Portanto, todas as atividades desenvolvidas foram essenciais, pois contribuíram para a limpeza do ambiente, para a socialização do conhecimento, para a sensibilização ambiental, e para o enriquecimento pessoal e profissional de todos os participantes e dos autores deste trabalho.

\section{REFERÊNCIAS}

ABNT, Associação Brasileira de Normas Técnicas. NBR 10004:2004: Resíduos sólidos - Classificação. Rio de Janeiro, 2004. Disponível em < 
http://www.aslaa.com.br/legislacoes/NBR\%20n\%2010004-2004.pdf > Acesso em: 23 de fev. 2015.

ALONSO, L. R. Coleta, tratamento e disposição final: problemas e perspectivas. São Paulo: Pini, 2001. Ambiente Brasil. Educação Ambiental. Conceito. Disponível em <http://www.ambientebrasil.com.br/composer.php3?base $=. /$ educacao/index.php3\&conteudo=./educacao/educacao.html> Acesso em: 23 fev. 2015.

GALLO, A. C. P.; GUENTHER, M. Reciclagem e reutilização de resíduos: um projeto socioambiental desenvolvido na educação de jovens e adultos (EJA) do SESC Santo Amaro, Recife (PE). Revbea, São Paulo, v. 10, n. 4, p.11-23, 2015.

GUIMARÃES, M. A dimensão ambiental na educação. Campinas, São Paulo: Papirus, 1995.

LOPES, T. C. S. Educação Ambiental como estratégia de sensibilização ambiental em uma escola de ensino médio, Angicos/RN. Monografia apresentada ao curso de Ciência e Tecnologia, UFERSA, Campus Angicos, 2011. Disponível em < http://www2.ufersa.edu.br/portal/view/uploads/setores/232/ arquivos/Thais\%20Cristina\%20de\%20Souza\%20Lopes\%20TCC_BDM_BCAUFE RSA\%202011.2.pdf > Acesso em: 23 fev. 2015.

MARTINS, C. P.; SANTOS, L. A.; OLIVEIRA, R. A.; ALVES, S. F. A necessidade de um melhor gerenciamento dos resíduos sólidos no município de Aparecida de Goiânia. Enciclopédia Biosfera, Centro Científico Conhecer - Goiânia, v.7, n.12, p. 1-12, 2011.

OLIVEIRA, K. J. M.; MEDEIROS, D. H. Educação ambiental: Abordagens teórico - metodológicas. V. EPCT, Encontro de Produção Científico e Tecnológico, 2010. Disponível em <http://www.fecilcam.br/nupem/anais_v_epct /PDF/ciencias_humanas/13_OLIVEIRA_MEDEIROS.pdf > Acesso em: 23 fev. 2015.

OLIVEIRA, A. L.; SOUZA, P. A.; GONÇALVES, D. S.; SANTOS, A. F.; BENDITO, B. P. C. Análise qualitativa dos impactos ambientais no meio abiótico em um depósito de resíduos sólidos. Enciclopédia Biosfera, Centro Científico Conhecer - Goiânia, v.11, n.22, p. 184-199, 2015.

RIBEIRO, J. A.; ALBURQUERQUE, J. de L.; SILVA, D. M. da C. S.; NAVAES, A. M.; JÚNIOR, G. C. C. A reciclagem como uma ação econômica, social e ambiental: a experiência da associação dos agentes de reciclagem do Ipojuca-PE. SOBER, Campo Grande-MG, 2010. Disponível em < http://www.sober.org.br/palestra/15/663.pdf > Acesso em: 23 fev. 2015.

SILVA, E. A.; OLIVEIRA, C. A. M.; CUNHA, R. R. C. A.; SOARES, R. V. S.; TEIXEIRA, V. D.; GUENTHER, M. Educação ambiental voltada para a reutilização e reciclagem dos resíduos sólidos no ambiente escolar: um estudo de caso no 
ensino fundamental em Recife(PE). Revbea, São Paulo, v.9, n. 2, p. 412-423, 2014.

SPIRONELLO, R. L.; TAVARES, F. S.; SILVA, E. P. Educação ambiental: da teoria à prática, em busca da sensibilização e conscientização ambiental. Revista Geonorte , Edição Especial, v.3, n.4, p. 140-152, 2012. 